\title{
Extending the social justice mindset Implications for scholarly communication
}

I n 2016, the Collections Directorate of the MIT Libraries convened a Diversity, Inclusion, and Social Justice (DISJ) Task Force to explore ways to manifest DISJ values in our daily work. Eight staff from archives, technical services, preservation, scholarly communication, and collections strategy focused on this question: How can we operationalize the values of diversity, inclusion, and social justice in our policies, routines, and processes?

Inspired by discussions involving every member of the directorate, as well as work done by other libraries and archives, the task force developed more than 40 recommendations in four categories: The Scholarly Publishing and Academic Library Marketplace; Representation of Marginalized Perspectives; Community Inclusion and Outreach; and Building Organizational Infrastructure for Diversity, Inclusion, and Social Justice. The task force released a preliminary report in November 2016 and the final version in February 2017. ${ }^{1}$

The report argues that broad, historically rooted, and global forces structure economics, culture, and society, including higher education and the library profession. These forces include neoliberalism, an economic and political ideology that is expressed, in part, in the commercialization of scholarly publishing and in the "increasing reliance by academic libraries on corporate solutions for many of our basic functions." 2

Structures of social power are also at work, including "systems of oppression and privilege that disempower or elevate people according to social and cultural categories such as race, gender, religion, sexual orientation, gender expression, class, and ability." In addition, we are "situated within global structures of power that have their origins in histories of racialized imperialism, war, and economic exploitation."

However, our professional values (such as ALA's Core Values of Librarianship and SAA's Core Values Statement and Code of Ethics) place us in opposition to these systems. This fundamental argument - that we must apply our professional values to the reality of structural inequity to guide our actions-shaped the report's recommendations.

These recommendations spanned the work of the Collections Directorate, including perspectives from each department, and a number of them are currently in progress. For example, the Collections Strategy and Assessment team has a project underway to update the GOBI approval plan to more efficiently build inclusive collections. We are also compiling proposals to present to GOBI to facilitate inclusive collection-building across their library customer base (for example, by adding awards, review sources, and publishers that reflect DISJ values to the book profiling process). A review and revision

Michelle Baildon is collections strategist for arts and humanities and science, technology, and society librarian at MIT Libraries, email: baildon@mit.edu

() 2018 Michelle Baildon 
of collection development policies in the arts, humanities, social sciences, and management to better include works by and about diverse groups and voices will begin later this spring.

\section{Understanding scholarly communication through the DISJ lens}

Below I share reflections about possible implications from the antiracist and anticolonial position suggested by the DISJ Task Force Report for scholarly communication discussions and initiatives. These are my own reflections as a task force member and not an official representation of MIT Libraries' views or policies.

\section{Expanding access to consumption and participation}

The task force embraced the Open Access (OA) movement as social justice work, but also cautioned us to be aware of the limitations of OA within our DISJ framework. The report takes note of the "danger of focusing on access but not participation. Our goal should be equitable global scholarly exchange rather than a one-way bestowal of knowledge from the Global North to the Global South." ${ }^{\prime}$ This argues for consistent application of our critique of power disparities not only to external actors and long-standing professional practices, but also to new solutions we devise.

The social justice imperative for North American and European OA initiatives is clear: OA is one of our most powerful tools to dismantle a global system of information privilege. These initiatives liberate the scholarship of Global North institutions for consumption in the Global South. But what about scholarly production? Easier flow of publications from North to South can also, in fact, increase publication opportunities for Global South scholars, simply by making the latest high-profile scholarship available for these scholars' use. Yet there are limitations to an approach that leaves in place structural power imbalances. ${ }^{5}$

Dwai Banerjee of MIT's Program in Science, Technology, and Society described, in a recent email exchange, the problem of "prestige asymmetry" between North and South. Banerjee observes that many American scholars are aware of scholarship coming from India, "but choose not to use it, because academia does not value scholarship from other places. This plays into citational politics, not out of ignorance of work done elsewhere, but as a matter of academic convention." He sees Global South scholarship being treated as "data" by North American and European researchers rather than a true part of the academic conversation. Entering that conversation requires publication in the "right" (North American or European) journals, which is impossible without access to the most recent scholarship from those same journals. Consumption access can thus translate into participation access by making it easier to gain publication in journals from the North, which then yields recognition in the form of citation by academics in the North. ${ }^{6}$

This North-to-South flow of scholarship can thus contribute to some subsequent Southto-North flow. The overall effect, however, is not to create a more equitable system, but rather to improve the chances of a Global South scholar participating effectively within a colonized system.

April Hathcock writes about the "colonialism of scholarly communication," noting that most conversations about scholarly communication are "centered around, directed by, and saturated in the values and ideals of the white North American and Western European, neoliberal researcher." This colonialism is demonstrated by pressure on Global South researchers to cite North American and European rather than local scholars, as well as institutional incentives to publish in high-profile Western journals. Meanwhile, publications by and for the Global South-many of which cover regionally relevant topics neglected elsewhere-remain undervalued and underused.

This problem could, ironically, be exacerbated by the growth of OA in the Global North. Laura Czernowicz, director of the University of Cape Town's Centre for Innovation in Learning and Teaching, referring to new 
OA policies in the UK and EU, argues that the "danger of this more ubiquitous availability is that without similar national and regional policies in the developing world, and without resources being made available to actively support open dissemination in these countries, many types of research from the developing world will be rendered even more invisible."

\section{The possibility of decolonization and a healthy global scholarly communica- tion system}

How, then, to foster a truly global scholarly communication system founded on equitable knowledge exchange? A possible first step would be to devote more resources to supporting the flow of OA from South to North, in addition to efforts to support OA for our own authors through institutional repositories, publication funds, etc. This might include contributing funding to OA initiatives originating in the Global South, such as SciELO or Redalyc, or contributing to efforts that explore means other than APCs to fund OA publication. Keeping in mind structural barriers to participation in the traditional publishing stream, we might also pay attention to alternative formats. Czernowicz notes that research from the Global South, especially on development issues, can skew towards the (often lessvalued) "grey literature" of working papers, technical reports, and policy reports.

We must take care to pursue these ventures with a spirit of true partnership. As Hathcock puts it, "Those of us from the global north need to acknowledge the harm our neoliberal colonizing has done to scholarship around the world and take responsibility. Then, we need to step back and listen." As Hathcock suggests elsewhere in her blog post, if we listen, we might find that OA isn't the only answer for researchers in the Global South. If we intend to support (financially and access-wise) publications by and from the Global South, and if we are vigilant about not imposing our values, we might find that this support most readily consists of subscriptions to paid-access journals, possibly including print publications. Comprehensive OA for scholarly publications from the Global South might be the ideal, but assuming that achievement of the ideal isn't imminent, we might consider other means to offer material support for these publications and to make them available to our researchers. One such model is that of African Journals Online (AJOL), which hosts a combination of OA and paid-access journals. AJOL offers libraries a prepaid article download account, the income of which is used in cost-recovery by AJOL and returned to the originating journals. ${ }^{10}$

\section{Missing voices: Is scholarly communi- cation enough?}

If we acknowledge, as the DISJ Task Force report suggests, that white supremacy and heteronormative patriarchy are pervasive and affect all stages of scholarly and scientific production, where does that train of thought take us? Not only librarianship, but also the publishing industry, our vendors, and higher education itself exist in these structures of power that operate both globally, as discussed above, and within North American and European contexts. Because of these inequities, people are squeezed out at every possible point of participation in educational and scholarly communication systems. What about the voices that never even made it into the system?

A genuine commitment to diversity, inclusion, and social justice prompts us to seek these missing voices. Disparities in access and representation are still all too common in higher education-in particular in STEM fields-and in the media. ${ }^{11}$ Some of the voices excluded from science and engineering might be found in other disciplines. Those excluded from higher education might be found in fiction, music, or other cultural expression. Those excluded from mainstream commercial cultural expression might be found in self-published or alternative publications. And some will only be recorded if we seek them out, through oral 
history, ephemera, or community archiving and post-custodial collections.

As libraries increasingly do the necessary work of making our own institutions' publications open, we should also acknowledge that these institutions are themselves structured by inequity. They exist in a context of global power disparities, and, in the case of elite institutions, have historically reflected privilege and oppression. A focus on OA limited to elite research outputs risks reproducing structures of power.

\section{Conclusion}

The approach of the DISJ Task Force Report is to tie top-level concepts and fundamental assumptions to practical, local actions. We intended first to recognize and articulate systems of injustice, and then identify on-theground ways to counteract, resist, dismantle, and redress them. Our focus was also human-level-including the current condition of real people (in our workplace and the MIT community)—and not only on abstractions and large-scale systems.

If we take this framework of diversity, inclusion, and social justice as our fundamental approach, what are the implications for how we approach problems in scholarly communication? Fixing the broken scholarly communication system is certainly one aspect. However, the DISJ Task Force framework suggests that we take a broad view of (or beyond) scholarly communication in order to include all voices in our collections. If we focus on the needs of real people, right now, we must remain flexible with our proposed solutions. The critical self-reflection of DISJ consciousness requires that we keep sight of the role of academic libraries as cultural heritage - and not just scholarly communication-institutions.

\section{Notes}

1. Michelle Baildon, et al., "Creating a Social Justice Mindset: Diversity, Inclusion, and Social Justice in the Collections Directorate of the MIT Libraries," (February 14, 2017) http:// hdl.handle.net/1721.1/108771.

2. Ibid., p. 4 .
3. Ibid., p. 5.

4. Ibid., p. 11.

5. The MIT Future of Libraries Task Force Report recognizes the promise of global access to MIT research for a truly robust exchange of ideas, including those previously excluded from the conversation due to lack of access. It also acknowledges the risk of paternalism in this approach, recommending sharing not only content, but also tools for collaboration, Institute-Wide Task Force on the Future of Libraries, Preliminary Report (October 24, 2016): 11, https://future-of -libraries.mit.edu/.

6. Dwai Banerjee, email message to author, January 31, 2018.

7. April Hathcock, "Making the Local Global: The Colonialism of Scholarly Communication," At the Intersection: Blog About the Intersection of Libraries, Law, Feminism, and Diversity (September 27, 2016), https:// aprilhathcock. wordpress.com/2016/09/27 /making-the-local-global-the-colonialism-of -scholarly-communication/.

8. Laura Czernowicz, "Inequitable Power Dynamics of Global Knowledge Production and Exchange Must Be Confronted Head On," LSE Impact Blog (April 29, 2013), http://blogs.lse.ac.uk/impactofsocialsciences /2013/04/29/redrawing-the-map-from -access-to-participation/.

9. Hathcock, "Making the Local Global."

10. "How Librarians Can Use AJOL," African Journals Online, https://www.ajol.info /index.php/ajol/pages/view/how-librarians -can-use-AJOL, accessed February 26, 2018.

11. Mica Estrada, et al., "Improving Underrepresented Minority Student Persistence in STEM," CBE Life Sciences Education, 15, no. 3, (Fall 2016): 1-10; U.S. Department of Education, Advancing Diversity and Inclusion in Higher Education: Key Data Highlights Focusing on Race and Ethnicity and Promising Practices, November 2016, www2.ed.gov /rschstat/research/pubs/advancing-diversity -inclusion.pdf. See also Annenberg Inclusion Initiative reports on media representation, http://annenberg.usc.edu/research/aii, accessed March 5, 2018. 